\title{
Reliability of the Information About the History of Diagnosis and Treatment of Hypertension. Differences in Regard to Sex, Age, and Educational Level. The Pró-Saúde Study
}

\author{
Eduardo Faerstein, Dóra Chor, Claudia de S. Lopes \\ Rio de Janeiro, RJ - Brazil
}

\begin{abstract}
Objective - To assess the intraobserver reliability of the information about the history of diagnosis and treatment of hypertension.
\end{abstract}

Methods - A multidimensional health questionnaire, which was filled out by the interviewees, was applied twice with an interval of 2 weeks, in July '99, to 192 employees of the University of the State of Rio de Janeiro (UERJ), stratified bysex, age, andeducational level. The intraobserver reliability of the answers provided was estimated by the kappa statistic and by the coefficient of intraclass correlation (CICC).

Results - The general kappa ( $k$ ) statistic was 0.75 (95\% CI=0.73-0.77). Reliability was higher amongfemales $(k=0.88,95 \% C I=0.85-0.91)$ than among males $(k=0.62,95 \% C I=0.59-0.65)$. The reliability was higher among individuals 40 years of age or older $(k=0.79 ; 95 \%$ $C I=0.73-0.84)$ than those from 18 to 39 years $(k=0.52$; $95 \% \mathrm{CI}=0.45-0.57)$. Finally, the kappa statistic was higher among individuals with a university educational level $(k=0.86 ; 95 \% C I=0.81-0.91)$ than among those with high school educational level $(k=0.61 ; 95 \% C I=0.53$ $0.70)$ or those with middle school educational level $(k=0.68 ; 95 \% C I=0.64-0.72)$. The coefficient of intraclass correlation estimated by the intraobserver agreement in regard to age at the time of the diagnosis of hypertension was 0.74 . A perfect agreement between the 2 answers $(k=1.00)$ was observed for 22 interviewees who reported prior prescription of antihypertensive medication.

Conclusion - In the population studied, estimates of the reliability of the history of medical diagnosis of hypertension and its treatment ranged from substantial to almost perfect reliability.

Keywords: hypertension, reliability of results, questionnaires

Instituto de Medicina Social - UERJ

Mailing address: Eduardo Faerstein - Rua Sacopã, 191/201 - 22471-180 - Rio de Janeiro, RJ, Brazil

English version by Stela Maris C. Gandour
Estimates of prevalence of hypertension in some Brazilian regions ranged from $11 \%$ to $25 \%$ of the adult population in the $90 \mathrm{~s}^{1-4}$, because of an increase in the frequency of some of its risk factors, such as dietary issues ${ }^{5}$, overweight ${ }^{6}$, and stress of a psychosocial nature ${ }^{7,8}$. Therefore, epidemiological studies on hypertension have gained an increasing relevance in our country.

Direct measurement of blood pressure is not always feasible in multidimensional studies. In such cases, information provided by the interviewee in regard to the diagnosis of hypertension, as an approximation to the prevalence of the disease, is usually used because, in this way, the frequency of clinical diagnosis is actually measured, in addition to its understanding and acceptance by the interviewee $^{9-12}$.

Assessment of the quality of the information obtained in medical-epidemiological surveys is always important either by direct measurements, or questionnaires, or any other method. Criteria such as validity and reliability are used for this assessment. Validity of a measurement is the degree to which a measurement appropriately measures what it is intended to measure, ie, how the measurements compare with the established gold standard. Reliability, on the other hand, involves stability and equivalence of repetitive measurements of the same concept or phenomenon; therefore, reliable estimates, in most situations, relate to the extension with which a measurement provides consistent results, when replicated at another time in the same participants (intraobserver reliability), or when performed by different observers (interobserver reliability) ${ }^{13,14}$.

In the United States, estimates of the intraobserver reliability of the most used question for estimating the prevalence of hypertension in population studies ("Have you ever been told by any physician or health professional that you have hypertension, ie, high blood pressure?") ranged from 0.74 to 0.82 (kappa statistic, according to Methods) in 3 different studies using telephone survey ${ }^{9-11}$. According to the range proposed by Landis and Koch ${ }^{15}$, these results 
of the kappa statistic may be classified as a substantial reliability (0.60-0.79) or an almost perfect reliability (0.80-1.00).

In our study, we report the results of the intraobserver reliability of the history of medical diagnosis of hypertension and its treatment. To the extent it was possible to identify, it is the first attempt in our country to investigate the quality of the information reported regarding the history of hypertension.

\section{Methods}

We carried out a study on reliability through the application of the same questionnaire twice in a time interval of 2 weeks, according to criteria established in the literature ${ }^{13,14}$. This study relates to a cohort analysis that aims to study social determinants of physical and mental morbidity, and also health practices and care, in 4,030 effective technical and administrative employees of a public university in the state of Rio de Janeiro.

Intraobserver reliability was analyzed in a pilot study carried out in 192 technical and administrative employees hired in the same university. Selection of the participants aimed to allow reliable estimates, according to age, sex, and educational level, with a reasonable statistical accuracy. Aiming at this, subsamples of similar sizes were randomly selected in strata resulting from the crossing of these variables in the universe of approximately 1,000 eligible individuals.

Information was obtained through structured questionnaires that were filled out by the interviewees, who were divided into groups proctored by trained personnel, during a period of 30 to 40 minutes, after written consent was given by the participants. The interviewers did not know the responses provided by the interviewees in the 2 questionnaires.

The multidimensional questionnaire comprised, among other issues, the following: the history and present situation of social and economical conditions, and other aspects of the social life, such as experience with violence, social and racial discrimination, integration to social webs of support, and events of life that cause stress; dietary patterns, physical activity, tobacco (active and passive) and alcohol use; history of medical diagnoses and treatments; mental health; use of medication and of unconventional therapies; practice of prevention and early diagnosis; other behaviors and exposures with repercussions to health.

Questions regarding the history of diagnosis of hypertension are highly standardized questions, which have been used for several years in epidemiological surveys in diverse countries. The first question is: "Have you ever been told by any physician or health professional that you have hypertension, ie, high blood pressure?", which has the following options for answers: 1) "Yes, I have been told only once."; 2) "Yes, I have been told more than once, on different days.";3) "Yes, I have been told, but only during pregnancy."; and 4) "No.". In regard to the analyses presented in this study, the interviewees who answered options 1 or 2 were considered hypertensive; those choosing options 3 or 4 were not con sidered hypertensive. The hypertensive individuals were then asked, with the possibility of an open response, the following question: "At which age were you told, for the first time, that you had a high blood pressure?", and subsequently: "Have you already been prescribed a medicine to control high blood pressure?" ("Yes" or "No").

The questionnaires were manually graded by support research personnel and underwent double typing independently. The Epi-Info software was used for elaborating the data input screen, with automatic checking of invalid data; the remaining stages of the procedure and data analysis were performed with SPSS version 9.0 software.

Assessment of intraobserver reliability in the entire population studied and also in the same population stratified by sex, age, and educational level was performed through the kappa statistic and its 95\% confidence intervals [95\% CI (k)]. In this case, kappa values quantify the level of agreement between the responses given to the same questions by the interviewees on the 2 occasions, already corrected in regard to the level of agreement randomly expected. Briefly, it is the proportion of observed agreement not randomly attributable [proportion observed (Po) - randomly expected proportion (Pr)] in regard to the possible maximum agreement not randomly attributable [1.0 - randomly expected proportion $(\mathrm{Pr})]$, ie, $\mathrm{k}=(\mathrm{Po}-\mathrm{Pr}) /(1-\mathrm{Pr})^{14}$. For interpreting purposes, we used the reliability range suggested by Landis and Koch ${ }^{15}$, which was based on estimated values for kappa, as follows: almost perfect reliability $(0.80-1.00)$, substantial reliability $(0.60-0.79)$, moderate reliability $(0.41-$ $0.60)$, reasonable reliability $(0.21-0.40)$, poor reliability $(0-$ $0.19)$, and very poor reliability $(<0)$.

In regard to age at the time of the diagnosis of hypertension, which was treated as a continuous variable, we calculated the coefficient of intraclass correlation, which estimates the proportion of the total variability observed attributable to the variability between individuals. When used as an index of agreement between 2 measurements, age is a kappa statistic, whose values range from -1 to $+1^{16}$.

\section{Results}

Out of the 192 employees participating in the pilot study, 169 (88\%) answered the question used for classifying hypertension in both questionnaires (intraobserver), comprising, therefore, the population of our study. In regard to sex, age, and educational level, the individuals who did not answer this question were similar to those who did. The proportion of males studied (52\%) was similar to that of females studied, and the mean age was 39 years.

In the first application of the questionnaire, 29 employees were classified as hypertensive; out of these 29 employees, 23 $(79.3 \%)$ were confirmed in the second application (Table I). The remaining 6 employees were classified as nonhypertensive, according to the second application of the questionnaire. Out of the 140 employees classified as nonhypertensive in the first application, $134(95.7 \%)$ were confirmed in the second application. The kappa statistic corresponding to this level of agreement was estimated in 0.75 . 
Table I - Agreement of the history reported about diagnosis of hypertension in 2 applications (intraobserver) of a questionnaire. PróSaúde study, 1999.

\begin{tabular}{|lcccc|} 
& & $\begin{array}{c}2^{\text {nd }} \text { application } \\
\text { Nonhypertensive }\end{array}$ & \multicolumn{3}{c|}{ Total } \\
\hline $1^{\text {st }}$ application & Hypertensive & Non\% CI & \\
\hline Hypertensive & 23 & 6 & 29 & $0.750 .73-0.77$ \\
Nonhypertensive & 6 & 134 & 140 & \\
Total & 29 & 140 & 169 & \\
\hline
\end{tabular}

The reliability of the classification of hypertension varied in different social and demographic subgroups of the population (Table II). In regard to sex, the kappa statistic was estimated as 0.62 for males and 0.88 for females. The employee's age also influenced agreement, which was higher among employees who were 40 years of age or older $(\mathrm{k}=0.79)$ then among those under 40 years of age $(\mathrm{k}=0.52)$. Likewise, agreement on the information among the employees with a university educational level was higher than that in the categories with middle school educational level and high school educational level ( $\mathrm{k}=0.86 \mathrm{vs} \mathrm{k}=0.68$ and $\mathrm{k}=0.61$, respectively).

Information about the history of medical prescription of antihypertensive drugs was provided by $22(76 \%)$ employees out of the 29 classified as hypertensive in the population studied, both in the first and second applications of the questionnaire. The reliability of the answer to this item was $\operatorname{maximum}(\mathrm{k}=1.00)$, ie, a perfect agreement between the answers provided on both occasions. Of these 22 employees, 17 reported using antihypertensive drugs, and 5 reported not using any antihypertensive medication.

Finally, 22 individuals reported the age they were told for the first time they had hypertension. The coefficient of intraclass correlation, which measures the agreement between answers provided in the 2 questionnaires, was estimated in 0.74 . However, only 1 employee gave very divergent answers in the 2 applications of the questionnaire (49 and 12 years of age, respectively). In the analysis of sensitivity of the coefficient of intraclass correlation, we observed that, by excluding this employee from the calculation, the coefficient of intraclass correlation was estimated in 0.98 .

\section{Discussion}

Whenever possible, reliability or reproducibility of measurements or diagnoses should be formally assessed in medical and epidemiological surveys. Usually, validity of the measurements is considered a property inherent in the diagnostic method (questionnaire, examination, or any other measurement tool). Reliability, however, in a certain study is influenced by characteristics of the person who answers, by the quality of the training of the observers, and by other more specific processes ${ }^{13,14}$.

In our study, intraobserver reliability of the information about the diagnosis of hypertension varied from substantial to almost perfect in different population subgroups, except for the younger employees (under 40 years of age), among whom the agreement was only moderate. This result may be partially explained by the low prevalence of hypertension in young individuals, and the kappa statistic tended to present lower values ${ }^{15}$.

Most of the international information comparable to ours originates from North American studies carried out according to the Behavioral Risk Factor Surveillance System, which monitores trends of prevalence of several

\begin{tabular}{|c|c|c|c|c|c|}
\hline \multirow{2}{*}{$\frac{\text { Sex }}{\text { Males }}$} & \multirow[t]{2}{*}{$1^{\text {nd }}$ application } & \multicolumn{2}{|c|}{$2^{\text {nd }}$ application } & \multirow[t]{2}{*}{ Kappa } & \multirow[t]{2}{*}{$95 \% \mathrm{CI}$} \\
\hline & & Hypertensive & Nonhypertensive & & \\
\hline & Hypertensive & 10 & 4 & 0.62 & $0.59-0.65$ \\
\hline & Nonhypertensive & 5 & 63 & & \\
\hline \multirow[t]{2}{*}{ Females } & Hypertensive & 13 & 2 & 0.88 & $0.85-0.91$ \\
\hline & Nonhypertensive & 1 & 71 & & \\
\hline Age & & & $2^{\text {nd }}$ application & & \\
\hline \multirow[t]{3}{*}{ 18-39 Anos } & & Hypertensive & Nonhypertensive & 0.52 & $0.45-0.57$ \\
\hline & Hypertensive & 3 & 2 & & \\
\hline & Nonhypertensive & 3 & 82 & & \\
\hline \multicolumn{6}{|l|}{40 years } \\
\hline & Hypertensive & 20 & 4 & 0.79 & $0.73-0.84$ \\
\hline & Nonhypertensive & 3 & 52 & & \\
\hline Educational level & & $2^{\text {nd }}$ application & & & \\
\hline \multirow[t]{3}{*}{ Middle school } & & Hypertensive & Nonhypertensive & & \\
\hline & Hypertensive & 8 & 3 & 0.68 & $0.64-0.72$ \\
\hline & Nonhypertensive & 2 & 27 & & \\
\hline \multicolumn{6}{|l|}{ High school } \\
\hline & Hypertensive & 4 & 1 & 0.61 & $0.53-0.70$ \\
\hline & Nonhypertensive & 3 & 35 & & \\
\hline \multicolumn{6}{|l|}{ University } \\
\hline & Hypertensive & 11 & 2 & 0.86 & $0.81-0.91$ \\
\hline & Nonhypertensive & 1 & 69 & & \\
\hline
\end{tabular}


risk factors, habits, and health behaviors through telephone interviews with population samples in each state of that country. Reports of studies of intraobserver reliability identified in the literature in regard to hypertension, are limited to assessing the answers to the basic question: "Have you ever been told by any physician or health professional that you have hypertension, ie, high blood pressure?". Estimates of the kappa statistic for this information in 3 states of theUnitedStateswere 0.79 inNew York ${ }^{9}, 0.86$ in Missouri ${ }^{10}$, and 0.74 in Massachussets ${ }^{11}$, which are very similar to 0.75 , found in the population we studied. Stein et al ${ }^{11}$ reported specific estimates in demographic strata, as in our study. In contrast to our study, however, they observed a higher reliability among older individuals answering the questions, but they detected no differences in regard to sex or to educational level.

It is worth noting the excellent reliability of the information about the age of the diagnosis of hypertension and about the prescription of antihypertensive drugs among the individuals providing these data. However, out of the 29 participants reporting a history of hypertension, 7 (24\%) individuals did not answer those questions; we may suppose that if these individuals had answered the questions, the es- timates of reliability would have been more conservative. We have found no data in the literature in regard to the reliability of this information in other populations.

Direct measurement of blood pressure levels is desirable in population studies that investigate the magnitude of and factors associated with hypertension. Circumstances exist, however, in which this procedure is not feasible. Our study did not encompass the assessment of validity of the answer in regard to the values of hypertension; however, estimates based on the measurement of blood pressure and in questions about the history of medical diagnosis of hypertension do not strictly constitute indicators of the same phenomenon, because several undiagnosed cases exist. The use of the question is justified in specific populations. This is the case of the population we studied, employees of a university, which, compared with the general Brazilian population, have higher educational levels, a greater access to information and to health services, and, therefore, are more likely to have a medical diagnosis of hypertension. Likewise, in population groups with similar social and economical conditions, the application of the questions assessed in this study may be justified to give an approximate idea of the magnitude of hypertension and features associated with its treatment.

\section{References}

1. Rego RA, Berardo FAN, Rodrigues SR, et al. Fatores de risco para doenças crônicas não transmissíveis: inquérito domiciliar no município de São Paulo, SP (Brasil). Metodologia e resultados preliminares. Rev Saúde Publ SP 1990; 24 : 277-85

2. Lolio CA, Latorre MRDO. Prevalência de obesidade em localidades do Estado de São Paulo, Brasil, 1987. Rev Saúde Publ SP 1991; 25: 33-6.

3. Duncan BB, Schmidt, MI, Polanczyc CA, Homrich CS, Rosa RS, Achutti AC Fatores de risco para doenças não transmissíveis em área metropolitana da região Sul do Brasil. Prevalência e simultaneidade. Rev Saúde Publ SP 1993; 27: 43-8.

4. Klein CH. Hipertensão arterial nos estratos geo-econômicos do Rio Grande do Sul. Rio de Janeiro, 1984. Tese de Mestrado - Escola Nacional de Saúde Pública/ FIOCRUZ.

5. Mondini L, Monteiro CA. Mudanças no padrão de alimentação da população urbana brasileira (1962-1988). Rev Saúde Publ SP 1994; 28: 433-9.

6. Coitinho DC, Leão MM, Recine E, Sichieri R. Condições nutricionais da população brasileira: adultos e idosos. Pesquisa Nacional de Saúde e Nutrição, Ministério da Saúde, Brasília, 1991.

7. INCLEN Multicentre Collaborative Group. Socio-economic status and risk factors for cardiovascular disease: a multicentre collaborative study in the international clinical epidemiology network (INCLEN). J Clin Epidemiol 1994; 47: 1401-9.
8. Marmot, MG, Rose G, Hamilton PJ. Employment grade and coronary heart disease in British civil servants. J Epidemiol Comm Health. 1978; 32: 244-9.

9. Bowlin SJ, Morrill BD, Nafziger AN, Jenkins PL, Lewis C. Pearson TA. Validity of cardiovascular disease risk factors assessed by telephone survey: the Behavioral Risk Factor Survey. J Clin Epidemiol 1993; 46: 561-71.

10. Brownson RC, Jackson-Thompson J, Wilkerson JC, Kiani F. Reliability of information on chronic disease risk factors collected in the Missouri Behavioral Risk Factor Surveillance System. Epidemiology 1994; 5: 545-9.

11. Stein AD, Courval JM, Lederman RI, et al. Reproducibility of responses to telephone interview: demographic predictors of discordance in risk factor status. Am J Epidemiol 1995; 141: 1097-106.

12. Chor D. Hipertensão Arterial entre Funcionários de Banco Estatal no Rio de Janeiro: hábitos de vida e tratamento. Arq Bras Cardiol 1998; 71: 653-60.

13. Carmines EG, Zeller RA. Reliability and validity assessment. California, Sage Publications, 1979.

14. Szklo M, Nieto FJ. Epidemiology - Beyond the Basics. Gaithersburg, MD: Aspen Pub, Inc.

15. Landis JR, Koch GG. The measurement of observer agreement for categorical data Biometrics 1977; 33: 159-74.

16. Shrout PE, Fleiss JL. Intraclass correlations: uses in assessing raters reliability. Psychol Bull 1979; 86: 420-8. 